\title{
Pleurotus sajor-caju Mantar Yetiştiriciliğinde Bazı Bitkisel Sebze Artıklarının Kullanımı Üzerine Bir Araştırma
}

\author{
M. Ertuğrul JLBAY \\ Geliş Tarihi : 18.03 .2002
}

\begin{abstract}
Özet: Araştırma, sebze üretiminden sonra tarlada kalan ve kullanımayan bitkisel atıkların Pleurotus sajor-caju mantarının yetiştiriciliğinde kullanılabilirliğini belirlemek üzere gerçekleştirilmiştir. Çalışmamızda bitkisel atıkların direk hammateryal olarak kullanılmasının yanında, samana ilave edilerek de hazırlanan yetiștirme ortamlarının Biyolojik Verim Oranlarının tespitine çalışıımıştır. Araştırmada en yüksek verim \%42.73'lük BVO oranı ile atıkların samana 10:2 oranında katıldığı uygulamadan elde edilmiş, bitkisel atıkların kullanım dozuna paralel olarak veriminde düştüğü gözlenmiş; en düşük BVO \%20.87 ile bitkisel atıkların direk hammateryal olarak kullanıldığı uygulamada ortaya çıkmışıิı. Yapılan araştırmanın sonunda bitkisel atıkların P.sajor-caju yetiştiriciliğinde direk hammateryal olarak kullanılamamasına karşın, katkı maddesi olarak rahatıkla değerlendirilebileceği ortaya konmuştur.
\end{abstract}

Anahtar Kelimeler: mantar, Pleurotus sajor-caju, bitkisel atık

\section{The Research on the Usage of Vegetable Waste for Pleurotus sajor-caju Mushroom Production}

\begin{abstract}
The aim of this research is to determine the usage of vegetable waste on Pleurotus sajor-caju mushroom production. In the experiments, vegetable waste is used not only as substrate but also supplementation to wheat straw. The highest, yield were obtained as $42.73 \% \mathrm{BE}$ at supplementation rate $10: 2$. With the increase of the rate of vegetable waste in the media, decreasing yield was obtained as $20.87 \% \mathrm{BE}$, when vegetable waste is used as substrate. The results of this research showed that while vegetable waste can not be used as substrate directly for Pleurotus sajor-caju mushroom production, it has high value as supplementation to the growing media.
\end{abstract}

Key Words: mushroom, Pleurotus sajor-caju, vegetable waste

\section{Giriş}

Dünyanın hemen hemen bütün Ilıman iklim bölgelerinde ölü ağaç kütüklerinin üzerinde yabanilerinin görülebildiği Pleurotus spp. Ülkemiz florasında da bulunmakta ve halkımız tarafından kayın, kavak, yaprak, dil mantarı olarak tanınmaktadır.Bugün dünyada en fazla beyaz şapkalı mantarın (Agaricus bisporus) üretimi yapılmaktadır.

Bununla beraber Pleurotus cinsi mantarların üretimi, yetiştiriciliğinin kolaylığı ile düşük üretim maliyeti, yüksek karlılığının yanında, besin değeri ve lezzeti bakımından da hızla yayılmaktadır. Nitekim günümüzde yaklaşık 6 milyon tonluk dünya mantar üretiminde $\% 25^{\prime}$ lik bir payla, toplam üretimin \%30'una sahip olan A.bisporustan sonra 2. sırada yer almaktadır (Poppe 2000, Anonymous 2002a, Anonymous 2002b)

Pleurotus cinsine giren P.sajor-caju ilk kez Jandaik adlı araştırıcı tarafından Hindistan'da Euphorbia roylena ağacının ölü odunlarından yetişmiş taze bir mantardan doku kültürü yöntemiyle çoğaltılarak kültüre alınmıştır (Roxon ve Jong 1977).

Odun tahripçisi saprofit bir fungus olan P.sajor-caju, misellerinin yuaksek kolonizasyon kabiliyetlerinden dolayı birçok tarımsal atık madde(hububat sapları, mısır koçanı, talaş, pamuk, yerfıstığı, tütün, kahve, kakao bitkisi atıkları vb.) yetiştiriciliğinde hammadde olarak kullanıllabilmektedir (Oei 1991, Zhanxi ve Zhanhua 1997, Anonymous 2002c, d).

\footnotetext{
${ }^{1}$ Ankara Üniv. Ziraat Fak. Bahçe Bitkileri Bölümü-Ankara
}

$P$.sajor-caju yetiştiriciliğinde uaretim yerleri ile üretim sistemleri, kullanilan hammateryaller ülkeden ülkeye, hatta bir ülkenin bölgelerine göre bile farklılık göstermekte, bunda da bölgenin veya alkenin ekonomik veya ekolojik koşulları büyük rol oynamaktadır. Bazı üreticiler açıkta doğa şartlarında üretim yaparken, bazıları modern mantar işletmelerinde üretimi gerçekleștirmektedir.Aynı durum, kullanılan materyaller için de geçerli olup, üreticiler en ucuza ve en kolay temin edebilecekleri tarımsal atıkları ham materyal olarak kullanmaya çalışmaktadırlar. Ülkemizde ve Bölümümüzde, P.sajor-caju'nun değişik tarımsal atıklar üzerinde yetiştiriciliğine yönelik bir çok çalışma yapılmış ve yetiştirme - koşulları ortaya konulmuştur (Ağağoğlu ve ark. 1992, Serdaroğlu 1995, İlbay 2000a). Bununla beraber mantar yetiştiriciliğinin temel amaçlarından biri olan atık maddelerin üretimde değerlendirilmesi göz önüne alındığında yapılan literatür taramalarında, ülkemizde sebze atıklarının bu konuya yönelik olarak kullanımına ait herhangi bir çalışmaya rastlanılmamıştır. Aslında her yıl üretim sonrası bir çok sebze bitkisi ya tarlada çürümeye bırakılmakta veya yakılmakta ya da sürülerek toprağa karıștırılmakta, bu durum belki de mantar üretiminde değerlendirilebilecek tonlarca hammaddenin ziyan olmasını gündeme getirmektedir.

Planlanan bu çalışma, sebzecilikte hasat sonrası kalan bitkisel atıkların P.sajor-caju üretiminde kullanılabilirliğini belirlemek üzere gerçekleştirilmiştir. 


\section{Materyal ve Yöntem}

Araştırma, 2000 eylül ile 2002 ocak ayları arasında Ankara Üniversitesi Ziraat Fakültesi Bahçe Bitkileri Bölümüne ait Misel Üretim Laboratuvarı ile Mantar Yetiştirme Ünitesinde gerçekleştirilmiştir.

Çalışmada Pleurotus sajor-caju'nun Ankara Üniversitesi Ziraat Fakültesi Bahçe Bitkileri Bölümü'nde çoğaltılan ATCC 32078 çeşidinin tohumluk miselleri materyal olarak kullanılmış, buğday samanı piyasadan satın alınmıştır.

Araştırmada sebze atığı olarak, biber (Capsicum annum), domates (Lycopersicon esculentum) ile fasulye (Phaseolus vulgaris) olmak üzere 3 çeşit bitkinin atığı kullanılmış ve söz konusu atıklar Bölümümüz sebzecilik parselinden hasat sonrasında elde edilmiştir. Hasat sonrası atıklar önce güneşte kurutulmuş ve nem içerikleri $\% 10-15$ düzeyine indirildikten sonra ardından $2-3 \mathrm{~cm}$ uzunluğunda kesilmiş ve denemede her üç bitki eșit oranda karıştırılarak kullanılmıştır. Yapılan analizlerde samanın azot içeriğinin $\% 0.56$, fosforun $\% 0.09$, potasyumun $\% 0.68$ olduğu tespit edilmiş, karışım halinde kullanılan sebze atıklarının ise azot, fosfor ve potasyum içeriğinin sırasıyla $\% 0.84, \% 0.12$ ve $\% 0.67$ olduğu belirlenmiştir.

Çalışmada samana bitkisel atıkların ağırlık esası üzerinden karıștırılmasıyla hazırlanan aşağıda belirtilen toplam 7 değişik uygulamanın karşılaştırııması yapılmıştır.
1. Saman
2. Saman +Bitkisel atık (10:1)
3. Saman+ Bitkisel atık (10:2)
4. Saman+ Bitkisel atık (10:3)
5. Saman+ Bitkisel atık $(10: 4)$
6. Saman+ Bitkisel atık (10:5)
7. Bitkisel atık

Kuru halde iyice karıştırılan uygulamaların nem seviyeleri su ilave edilerek $\% 65^{\prime}$ e çıkarılmış ve kireç ilave edilerek pH değeri 7.0'ye ayarlanmıştır. Yetiştirme ortamları daha sonra $22 \times 42 \mathrm{~cm}$ ebadındaki polipropilen torbalara $500 \mathrm{~g}$ olacak şekilde doldurulmuş ve $121^{\circ} \mathrm{C}$ 'de 1.5 saat otoklavda sterilize edilmişlerdir (Auetragul 1983, Royse 1985).

Sterilizasyon işleminin ardından yetiştirme ortamlarına misel aşılaması gerçekleştirilmiştir. Bu amaçla aşılama makası yardımıyla P.sajor-caju'nun miselleri sardırılmış, yaklaşık 15-20 buğday tanesi yetiştirme ortamlarına inokule edilmislerdir. Daha sonra misel

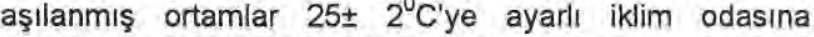
konulmuş ve gelişmeye bırakıımıştır.

19 günlük misel gelişim sonrası polipropilen torbalar çıkartılmış ve mantar oluşumu teşvik edilmiştir. Bu amaçla oda sıcaklığı $20^{\circ} \mathrm{C}^{\prime}$ ye indirilerek floresans lambalarla da günde 8 saat aydınlatma yapılmıştır. Bu dönemde ortamların kurumasını önlemek üzere oda neminin \%8090 arasında tutulmasına özen gösterilmiştir.
Araştırma Tesadüf Parselleri Deneme Desenine göre 3 tekrarlı ve her tekrarda 5 torba olarak kurulmuş elde edilen bulgular varyans analizi yöntemi ile değerlendirilerek Duncan Testi ile de uygulamalar arasındaki farklılığının önemli olup olmadığı tespit edilmiştir.

Denemede ilk 4 uygulamada hasada 25.günde başlanırken 5.uygulamada hasat 27,6 .uygulamada 28.günde başlamış ve toplam 30 günlük bir hasat süresi esas alınmıştır. Hasat süresince de bakım ve sulama işlemleri kültürün gerektirdiği şeklinde yerine getirilmiştir.

Çalışmada verimle beraber yetiştirme ortamlarının biyolojik verimlilik oranları (BVO) aşağıda belirtilen şekilde hesaplanmıştır (Royse 1985).

BVO $(\%)=\frac{\text { Hasat edilen taze mantar ağırlığı }(\mathrm{g})}{\text { Yetiştirme ortamının kuru ağırlığı }(\mathrm{g})} \times 100$

\section{Bulgular ve Tartışma}

Pleurotus sajor-caju'nun yetiştiriciliğinde sebze atıklarının kullanımına yönelik olarak 30 günlük hasat süresi sonunda verimlilik üzerine etkisini gösteren deneme sonuçları Çizelge 1'de verilmiştir:

Yapılan çalışma sonucunda ilk 15 günlük dönemde en yüksek verim $60.33 \mathrm{~g} /$ torba ile saman ve bitkisel atıkların 10:2'lik karışımında elde edilmiş, bunu 57.10 g/torba ile 4 ve 56.49 g/torb ile 5 no'lu karışım izlemiştir. $\mathrm{Bu}$ dönemde en düşük verim $33.28 \mathrm{~g} /$ tọrba ile sadece bitkisel atığın kullanıldığı 7 numaralı karışımda belirlenmiştir.

Íkinci on beş günlük dönemde en yüksek verim yine saman ve bitkisel atığın 10:2 oranındaki karışımından elde edilmiş ( $25.14 \mathrm{~g} /$ torba), bunu $18.86 \mathrm{~g} /$ torba ile saman uygulaması izlemiş, saman ve bitki atıklarının 10:3 oranında karıştırıldığı 4 no'lu karışım 14.36 g/torba ile 3 . sırada yer almıștır. Sadece bitki atığının kullanıldığı 7 no'lu uygulama bu dönemde de $9.47 \mathrm{~g} /$ torba ile yine en düşük verimi oluşturmuştur.

Çizelge 1. Bitkisel atıkların P.sajor-caju'nun verimine etkis

\begin{tabular}{|c|c|c|c|c|}
\hline \multirow{2}{*}{ Uygulamalar } & \multicolumn{3}{|c|}{ Verim (g/torba) ${ }^{*}$} & \multirow{2}{*}{$\begin{array}{l}\text { Biyolojik } \\
\text { verimlilik } \\
\text { oranı }(\%)\end{array}$} \\
\hline & 1-15, gùn & 16-30.gün & Toplam & \\
\hline 1. Saman & $43.27 b$ & $18.86 \mathrm{ab}$ & $62.13 \mathrm{~b}$ & 31.06 \\
\hline $\begin{array}{l}\text { 2.Saman+BA } \\
(10: 1)\end{array}$ & $55.92 \mathrm{ab}$ & $14.25 \mathrm{~b}$ & $70.17 \mathrm{ab}$ & 35.08 \\
\hline $\begin{array}{l}\text { 3.Saman+BA } \\
(10: 2)\end{array}$ & $60.33 \mathrm{a}$ & $25.14 \mathrm{a}$ & 85.47 a & 42.73 \\
\hline $\begin{array}{c}\text { 4.Saman+BA } \\
(10: 3)\end{array}$ & $57.10 \mathrm{ab}$ & $14.36 \mathrm{~b}$ & $71.46 \mathrm{ab}$ & 35.73 \\
\hline $\begin{array}{c}\text { 5. Saman+BA } \\
(10: 4)\end{array}$ & $56.49 \mathrm{ab}$ & $10.29 \mathrm{c}$ & $66.78 \mathrm{ab}$ & 33,39 \\
\hline $\begin{array}{l}\text { 6.Saman+BA } \\
(10: 5)\end{array}$ & $46.35 \mathrm{~b}$ & $12.21 \mathrm{bc}$ & $58.56 \mathrm{~b}$ & 29.28 \\
\hline 7. $\mathrm{BA}$ & $33.28 b c$ & $9.47 c$ & $41.75 c$ & 20.87 \\
\hline
\end{tabular}

* Farklı harfleri taşıyan uygulamalar arasında Duncan testine göre \%5 hata düzeyinde önemli farklılıklar vardır. 
Toplam verim bakımından 30 günlük hasat sonunda denemede en yüksek verim $85.47 \mathrm{~g} /$ torba ile samanla bitkisel artığının 10:2'lik karışımından elde edilmiş ve bu uygulamanın 1 no'lu saman ve 7 no'lu bitkisel atık uygulamasıyla aralarındaki fark istatiksel olarak önemli bulunmuştur.

Çizelgenin incelenmesinden de anlaşılacağı gibi, toplam verim bakımından 30 günlük hasat sonunda 4 no'lu uygulama 71,46 g/torba ile denemede 2., $70.17 \mathrm{~g} /$ torba ile 2 no'lu uygulama 3. sırayı almasına rağmen, her iki uygulama arasındaki farklılığın bulunmadığı, bununla beraber bitkisel atığın samana 10:2 oranının üstünde miktarların karıştırıldığında verim düşmesinin ortaya çıktığı görülmektedir. Nitekim 30 günlük hasat sonunda sadece bitki artığının yetiştirme ortamı olarak kullanıldığı 7 no'lu karışım $41.75 \mathrm{~g} /$ torba ile denemede en düşük değeri oluşturmuştur.

Sebzecilikte üretim sonrası tarlada kalan bitkisel atıkların Pleurotus sajor-caju yetiştiriciliğinde kullanılabilirliğinin araştırıldığı bu çalışmada en yüksek biyolojik verim oranı, samana $10: 2$ oraninda artığın katıldığı 3 no'lu uygulamadan elde edilmiş (\%42.73), bunu $\% 35.73$ 'lük BVO ile 4 no'lu uygulama [Saman+BA (10:2)] izlemiştir. Denemede atık miktarının artmasına paralel olarak verimin düştüğü gözlenmiş, nitekim en düşük BVO $\% 20.87$ ile atıkların sadece saf şekilde kullanıldığı 7 no'lu uygulamada ortaya çıkmıştır. Bununla beraber, bitkisel atıkların samanla yarı yarıya karıştırıldığı 6 no'lu uygulamanin 1 no'lu saman uygulaması ile arasında istatistiksel olarak bir fark bulunmaması bu atıkların P.sajor-caju yetiştiriciliğinde kullanılabilirliğinin mümkün olduğunu ortaya koymaktadır.

Araştırmalardan elde edilen bu sonuçlar, bir çok araştırıcının (Ganeshan ve ark. 1989, Poppe 2000, Singh 2000) sonuçları ile uyum içerisindedir.

Araştırmada en düşük verimin elde edildiği sadece bitkisel atıkların kullanıldığı 7 no'lu uygulamada $P$.sajorcaju misellerinin son derece zayıf geliştiği gözlenmiş, ayrıca kültür ortamlarında yoğun enfeksiyon tespit edilmiş, aynı durum, kullanılan atık miktarının daha fazla olduğu 5. ve 6. uygulamalarda da belirlenmiştir. Söz konusu konu kanımca; büyük ölçüde kullanılan bitkisel atıkların samanla olan fiziksel yapı farklılığından ileri geldiği ve sterilizasyon sonrasi bu atıkların enfeksiyon kapma hassasiyetleri bakımından daha duyarlı olması şeklinde açıklanabilir.

\section{Sonuc}

Bütün dünyada Pleurotus mantarlarının yetiştiriciliğinde hammateryal olarak hububat saplan ile talaş esas alınmakta ve bu ortamlar değişik katkı maddeleriyle zenginleştirilerek kullanılmaktadir. Aslinda dünyada ve ülkemizde yapılan çok sayıda araştırmada (Oei 1991, Zhanxi ve Zhanhua 1997, Ilbay 2000b, Illbay 2001), Pleurotus cinsi mantarların endüstriyel anlamda yetiştiriciliğinde yönelik uygun bir çok kompost formualü bulunmaktadır. Ancak her ülke, gelişen teknolojilerine paralel olarak kültür mantarcılığında kullanabilecekleri değişik atık maddeleri tespit ederek, bunları değerlendirme yoluna gitmektedirler.

Ülkemizin sebze üretim potansìyeli göz önüne alındığında azımsanmayacak ölçüde hammadde kaynağı olduğu ortaya çıkmaktadır. Yapılan bu çaliş̧ma sonuçlarına göre, sebzecilikte hasat sonrası bitkisel atıkların P.sajor-caju yetiştiriciliğinde temel bir hammadde olamayacağı açıktır. Bununla beraber, denememizde yer alan biber, domates ve fasulye sebzelerinin hasat sonrası bitkisel atıklarının P.sajor-caju yetiștiriciliğinde katkı maddesi olarak rahatlıkla değerlendirilebileceği ve verimi olumlu yönde etkilediği tespit edilmiştir.

Araştırmamız Ankara koşullarında gerçekleştirilmiş ve kullanilan bitkisel atıklar açıkta yetiştirilen sebzelerden elde edilmiştir. Yapılan gözlemlerde vegetasyon sonuna doğru bitkilerde hastalık oranı ile çürümeye olan meyilin artması ve yaklaşan kış koşulları atıkların yeterince kurumasını önleyebilmektedir.

Her ne kadar hava koşullarının iyi gitmesi nedeniyle hammateryallerin kurutulması bakımından denememizde böyle bir sorun yaşanmadıysa da, karşılaşılacak bu tür durumlarda atıkların en azından yapay yollarla kurutulmasının yararlı olacağı düşüncesindeyim.

\section{Kaynaklar}

Ağaoğlu, Y. S., M. E. Ilibay ve A. Uzun, 1992. Değişik talaş+kepek karışımlarının P.sajor-caju'nun verimi üzerine etkileri. Türkiye 4. Yemeklik Mantar Kongresi, (2) 111-119, Yalova.

Anonymous, 2002a.http://www hort purdue edu/newcrop/ proceedings $1996 / \mathrm{N} 3-476 \mathrm{html}$.

Anonymous, 2002b, http:/lusers.lbi.ro/ pilot/com.htm.

Anonymous, 2002c.http://www.mushroomcompany.com/ specialty.html.

Anonymous, 2002d.http://www.Mushworld.com.

Auetragul, A. 1983. Growing Mushrooms: Oyster Mushrooms, Jew's Ear Mushroom, Straw Mushroom. Food and Agriculture Organization of United Nations. $164 \mathrm{~s}$., Bangkok.

Ganeshan, G., R. P. Tewari and B. S. Bhangara, 1989. Influnce of residual vegetable crop biomass on yield and mineral content of P. sajor-caju (Fr.) Singer. Mushr. Sci., 12 (II) 91 97.

Ilbay, M. E. 2000a. Agaricus bisporus ve Pleurotus sajor-caju yetiștiriciliğinde vitamin katkısınin verim üzerine etkisi. Türkiye 6. Yemeklik Mantar Kongresi, 186-191, Bergama.

llbay, M. E. 2000b. Kültürü yapılan yenilebilir mantarlar. Türkíye 6. Yemeklik Mantar Kongresi, s: 1-37, Bergama.

Ilbay, M, E, 2001. Pleurotus sajor-caju mantarı yetiştiriciliğinde büyümeyi düzenleyici maddelerin kullanımının etkisi. Gıda 26 (1) 55-59.

Oei, P. 1991. Manual on Mushroom Cultivation. First edition. Toul Foundation, 249, Amsterdam.

Poppe, J. 2000. Use of agricultural waste materials in the cultivation. Mushr. Sci., 15 (1) 3-23,

Roxon, J. E. and S. C. Jong, 1977. Sexuality of edible mushroom P.sajor-caju. Mycologia, 69 (1) 203-205. 
Royse, D. J. 1985. Effects of spawn run time and substrate nutrition on yield and size of shiitake mushroom. Mycologia, 77 (5) 756-762

Serdaroğlu, C. 1995. Kültür Ortamlarının Değişik Miktar ve Şekillerde Paketlenmesinin Pleurotus Mantarının (P.sajorcaju) Verim ve Kalitesine Etkisi Üzerinde Araştırmalar.• Ankara Üniv. Fen Bilimleri Enstitüsü. Yüksek Lisans Tezi, Ankara.

Singh, P. M. 2000. Biodegradation of lignocellolosic wastes through cultivation of Pleurotus sajor-caju. Mushr. Sci., 15 (2) 517-521.

Zhanxi, L. and L. Zhanhua, 1997. Jun-Cao Technology. ONDP. China Sci. and Tech. Com. China, 130 s. 